\title{
Sustainable Wellbeing Society-A Challenge for a Public Sector Institution
}

\author{
Jari Salminen
}

\section{INTRODUCTION}

This article employs research into the history of education to examine the opportunities available to the public-sector school system to promote sustainable development and wellbeing. Research in the United States and Finland has long recognised certain persistent problems in terms of bringing about development and change in schools. The article analyses the main structural factors affecting operating cultures within schools and conflicting factors that steer school operations. They are revealed by the debate surrounding the duties of schools, institutional structures and curricula, and they stretch all the way to pedagogical activities and pupils' own actions. Awareness of these tensions must be increased if the aim is to promote broad-based societal goals such as sustainable development and greater wellbeing in education. Educational policy statements, think-tank visions and broad curriculum objectives are unable to eliminate these persistent tensions built into education and the public-sector school system.

J. Salminen $(\square)$

University of Helsinki, Helsinki, Finland

e-mail: jari.salminen@helsinki.fi

(C) The Author(s) 2019

J. W. Cook (ed.), Sustainability, Human Well-Being, and the Future of Education, https://doi.org/10.1007/978-3-319-78580-6_3 
In every state, public-sector school systems have formed as a result of a long historical development and, for this reason, they each have distinct characteristics. Changes in schools have coincided with broader societal and cultural changes in each state, as well as developments in economic activity and demographics. In spite of these differences due to state-level developments and society, every Western country has faced a very similar set of challenges in the development of its school institutions since the Second World War.

The accelerating development of society has given rise to a problem of tempo within schools: the need for continuous, comprehensive development and modernisation of operating modes. Changes in modern life and future expectations represent challenges to the implementation of school education in many ways. In 1999, James Gleick, an American non-fiction author and journalist, was considering the lives of ordinary Americans and remarked how everything was accelerating: love, life, speech, politics, work, TV and free time. And he is not alone in making that observation. Everything is subject to accelerating change: economics, weapons systems, construction, working life, the structural systems of society, cultural habits, norms and regulation, as well as physical and psychological conditions (Rosa 2009).

This Western pace of development has spread to all parts of life and all areas of the world. The history of the modern age is characterised by the acceleration of various technological, economical, social and cultural processes. Social scientists Hans van der Loo and Willem van Reijen (1992) have illustrated the pace of change by way of a 24-hour analogy. If the entirety of human development were condensed into a single day, more than 23 hours would have been consumed by the hunter-gatherer culture. Agriculture would account for four minutes, urban civilisations would get three minutes, and the modern world and its systematic education system would receive less than 30 seconds.

One common feature of Western development since the 1970s has been the intensification of efforts to solve large-scale, complex social problems and future challenges via school education. Attempts have been made to use schools to increase economic productivity, solve problems related to equality, integrate different cultural principles, make better citizens, promote health, and reduce traffic fatalities, juvenile delinquency, youth substance-abuse problems and obesity. A common feature of these constantly varying and diverse attempts to make a difference is the high frequency of failure. The positive effects have been often minimal, 
short-term or even non-existent in practice (Sarason 1990; Tyack and Cuban 1995; Labaree 2010; Salminen 2012).

Many efforts to reform schools are "wicked problems" in natureattempts to solve these are complex in many ways. From the perspective of planning based on a scientific worldview, solving these problems is prone to failure due to the complex nature of the problems. In their classic, frequently cited article of (1973), Horst Rittel and Melvin Webber, two American design theorists, outlined the features of wicked problems. According to them, science often works with "tame" problems. These can be precisely delineated and the conditions can be controlled. The process may be repeated, thereby enabling the results to be confirmed. However, societal issues, such as reforming school work to serve the objectives of sustainable development, cannot be definitively resolved. There are no objective answers to the question. It is a matter of social conditions that are almost impossible to control because not all of the variables in the process can be controlled-it may not even be possible for them to be identified. The phenomenon is unbounded, internally contradictory and constantly occurring under changing conditions. The selected solutions also give rise to new problems. The dynamic attained by a complex phenomenon is interactive in nature and this interaction is difficult to define even at the outset, often being non-linear, paradoxical and reorganising.

The fundamental task of education gives rise to two different and partially opposed approaches. In general it can be said that reformists consider school institutions to be a means of trying to change prevailing societal conditions, while traditionalists place a greater emphasis on the preserving function of education and culture. For this reason, publicsector school systems are forced to balance the contradictory forces of continuity and the future (change) at an accelerating rate. School education should reform tradition, societal and national values, and promote economic growth and competitiveness while preparing for future challenges in an increasingly complex and globalised, multicultural world threatened by the insufficiency of natural resources and the environment's capacity for endurance. Various educational efforts and explanations have set themselves up to address this dilemma.

In this complex undertaking, promoting the goals of sustainable development and wellbeing is a major challenge for the school system, requiring a thorough understanding of the institution's operations if real, lasting results are to be achieved. Promoting sustainable development 
and wellbeing is a typical wicked dilemma. It is difficult to create a consistent and logical objective for this dilemma. In and of itself, the objective contradicts certain other fundamental objectives and historically developed structures of the school.

\section{Vague Goals Do Not Lead to Results}

David Labaree (2010), a historian of education, has identified four systemic levels that form a hierarchy: the rhetoric, the institution, the teacher and the pupil. Efforts to promote the objectives of sustainable development and wellbeing come up against all of these challenges at different levels. Each of them has its own characteristics, actors and practices.

The top level, and the level furthest detached from the practical work of the school, is the rhetorical level. Reforms and new goals set for school usually originate here. The main actors are experts in various fields and professors, political and societally significant figures and lawmakers. Their leadership aims to promote a particular educational value, which is accepted as the new rhetorical aspiration to guide the school. The reformers' tools include a range of reports, policy programmes, strategy and vision papers, public speeches and scientific articles. However, in these various forums, it is very rare for clear and logical consensus to be reached regarding what schools should do and how the new objectives should be realised in practice. According to Stevenson (2007), there is an enormous difference between the political rhetoric of sustainable development and the educational practices of sustainable development.

Hannu Simola (2000), a Finnish educational sociologist, has defined a theoretical explanation of why public discourse on schools has become increasingly vague since the 1970s. In the US in particular, school reform has become a permanent part of school discourse- "steady work" as Elmore and McLaughlin (1988) put it. One reform follows another at a rapid tempo, and a new way of speaking replaces the old one before the previous reform has even been properly absorbed at the school level. In Finland, reform efforts have also constantly intensified since the 1970s.

According to Simola's research, four variables form the background of development rhetoric: the ethos of individualisation, the increasingly scientific approach to the field of education, the decontextualisation of discourse on education and the rationalisation of the objectives of curricula. Together, they form a way of talking about education that Simola 
has named the wishful rationalism. This refers to particular types of quiet truth. They are often recognised without being noticed in subordinate clauses, by implication between the lines, and are often not explicitly justified. They are often taken for granted, beliefs passed down, highly familiar but poorly known, widely recognised but rarely identified building blocks of a particular way of talking.

The objectives of school education have become more individualistic in recent decades. For most Western school systems, it has been typical to develop school to cater for the individual needs of pupils and families. Labaree (2010) refers to this desire among US schools as a consumerand market-driven change. This ideological aim has had an increasing effect on the work of schools since the 1990s. At the same time, the pupil's status and way of speaking about school have changed from traditional ideals of civic education towards a customer-oriented rhetoric that emphasises service capacity and performance. Charter schools and voucher models have rapidly altered the principles governing how education is arranged in several US states. This model, which favours individual school selection and enables schools to profile themselves and operate as profit-seeking commercial enterprises, has also been adopted in Sweden-particularly in the Stockholm region. In Finland, the development has not yet reached such an advanced stage but initial signals of a similar shift can already be detected in major cities. According to a study carried out by Sonja Kosunen (2016), middle-class parents in Helsinki and Espoo want to avoid disreputable schools and tend to look for alternatives for their children. These expectations also highlight the demand for more individualised service.

The emergence of a market for school education makes it more difficult to achieve various common and more general goals of civic education, such as promoting sustainable development. Such efforts are easy to formulate as part of development programmes and even as part of the curriculum, but are more difficult to implement in practical schoolwork in the form of consistent objectives. The conflict is exacerbated by more intense terminal evaluation procedures, which mechanically measure learning outcomes using a range of behavioural tests. Segregating schools into those with good reputations and those with bad reputations serves to accentuate the differences between schools. In such a competitive educational culture, it is essential for most families to primarily safeguard their own children's learning paths and subsequent career development by making the right choices. At the same time, schools 
lose the ability to respond to wider societal and common objectives as they increasingly head towards models that cater for customer needs created by ever-changing markets and trends in a climate of intensifying competition.

Discourse on the rationalism of hopes has also led to a kind of spiral of reform. From the very outset, the requirements for school reform are set increasingly further from the actual conditions in schools and, for this reason, they tend to fail. That is how this talk of reform decontextualised from the reality of education constantly leads to new requirements for the development of education. A situation has arisen in which the temporal, material and mental resources available to schools are becoming increasingly blurred. School developers and parties who set new educational missions for schools no longer recognise the school's historically constructed nature, its group-oriented and compulsory character, and multitude of internal contradictions and boundary conditions within its operations. There is no longer any argumentation of the school as a school with realistic starting points. There is less discussion about what school reality is, but there is more and more talk of what it should be (Simola 2000).

However, development and new requirements are often justified using scientific arguments and with reference to research results. Has modern educational science itself fuelled these unrealistic demands for changes to school development and the belief in solutions to societal problems? As many researchers have shown, reform efforts often depict the school as a mechanical system that operates like a machine and that can be fed new system components to be used alongside the old ones without any compatibility issues (Salminen 2012). By operating in this way, consultants and school reformers reinforce talk of reform ever further. At the same time they promise to parties outside the school-particularly familiesthat schools will perform these tasks. This further strengthens a belief in the ability of educational institutions to solve current and ever-expanding future problems.

Changing schools so as to serve the goals of promoting sustainable development and wellbeing is typical of attempts towards the rationalism of hopes. The objectives of the reform are easy for most interest groups to accept on a general rhetorical level when it is neither necessary to precisely define the contents of the objectives nor to consider conflicting factors within the objectives in relation to the school's other objectives and the boundary conditions of the school's operations. Efforts can also 
be justified using scientific results: the state of the environment must be taken into greater account in the future and, for example, action must be taken to halt the greenhouse effect. These objectives can be written into public statements and strategic texts related to school development, and they can extend all the way to school curricula. However, a closer analysis reveals many internally contradictory factors within the objective in relation to the structural tensions and the range of tasks in the school institution. In addition, overly vague objectives do not provide support for the real basic work of schools.

At the same time, it is necessary to be aware of the school's one key task. It is responsible for separating out pupils onto different education pathways by means of various diplomas, certifications and grades. The links between these certifications and economic growth, competitiveness and working life give risk to highly conflicting requirements from the perspective of sustainable development, along with different rhetoric in the discourse surrounding education.

The rhetorical level of the school hierarchy is very open to various new ideas of this type regarding what schools should be doing and where society's problems lie. However, these texts or speeches are not presented very clearly or logically from the perspective of practical operations. As reform goals become more extensive and the intended impacts reach ever further, it becomes more challenging to use them to bring about the desired direction of change in schools. According to Labaree (2010), this upper rhetorical level is where most school development efforts become stuck. The visions and programmes never affect everyday life in classrooms or pupils' mindsets. At the same time, there are also several other reform efforts underway at the operational level of schools, which are often at odds with each other. They compete within the system for the attention of teachers, pupils and parents.

In order to actually realise the rhetorical objectives at the school level, they must be expressed as clear goals to which the subsequent levels of the system are committed. This is how real problem solving should function. To overcome the task, a model would be created to bring together all of the information needed to understand and control the phenomenon. For schools, this is not possible. In order to understand a wicked problem with sufficient accuracy, all of the imaginable solutions associated with it would need to be considered. Each of them would require additional information. As regards school education, the information 
necessary to understand the solution depends on the idea that will be used to solve the problem.

In this example, the requirement that schools adapt to support sustainable development is an extremely broad and complex goal: what does it mean? How should it be implemented in schools? Which subjects are responsible for it and in what extent and depth? When can we say that the change has begun and when can we say that it has been implemented? Is it all about improving learning outcomes, changing attitudes or long-term consequences? Most likely, these would only be some of the requirements and factors for analysis. How should these be measured? Which of the results will be due to the activities of the school and what are the effects of the home and other variables? How can they be separated from school activities? The result is an endless number of new questions. Identifying the problem is the same thing as solving the problem. Formulating the wicked problem is the problem itself.

\section{Persistent Value Tensions in Schools}

In the model proposed by Labaree (2010), the second level of the hierarchy is the school's institutional formal structure. It is a historically developed, complex, bureaucratic, massive system. It consists of a school administration system (administrators, school districts), educational programmes and lesson allocations, legislation related to teaching, inspection and surveillance procedures, evaluation systems, teaching materials and workshops. The actors are representatives of the school administration, members of committees and management groups, educators, curriculum specialists and textbook publishers. At the rhetorical level, the opportunities to influence this formal structure are problematic in many ways. For example, in the United States alone, there are approximately 14,000 school districts, each with their own organisational form, local customs and values. Even in a small country such as Finland, the municipal school administration includes more than 300 units, and they have their own school districts. In addition, all Western countries have private schools, which generally have different principles and characteristics than those used in the public-sector school system.

Education objectives from the rhetorical level are proposed at the institutional level with the aid of curricula and various school 
development programmes. The intention is to use these to attempt to steer this massive system in the desired direction. However, the curriculum is not a clear, neutral, logical document-it is an ideological, multi-levelled, fragmented and ambiguous collection of text about various educational tasks. John I. Goodland (1979), an American education researcher, posed an incisive question about the vagueness of the concept of a curriculum: who has the right to determine what course content is worthy to be described as a curriculum? Education historian Lawrence Cremin (1987) has pointedly asked whether all institutions have official curricula: the church, the family, even the TV channel? American curriculum expert Joseph Schwab (1978), in turn, noted in the 1970s that all curricular theories are imperfect. According to him, theory is only useful if it has practical applications.

Political power is reflected at the institutional level in other ways than via the school curriculum. Education is steered by a multitude of laws, while programmes, research and development work are sponsored by political entities. There are regulations governing teachers' qualifications and the effectiveness of education is evaluated. One of the most visible effects of politics, specifically on the development of the American school system, was "Sputnik shock", when the Soviet Union launched its own shuttles into space during the Cold War. The result was a strong emphasis on mathematical and scientific subjects because decision-makers felt the US was falling behind the Soviet Union in terms of technological development. In Finland, similarly powerful, rapid changes have been made to the focuses of curricula as a result of state-level crises. Russia's administrative machinery made a strong intervention with regard to lesson allocations when the policy of assimilation began in 1899. After the Civil War, Finnish folk schools became instruments of the national policy of assimilation. This nationalist ethos of the school reached the end of the road in the autumn of 1944. The collapse of the Soviet Union and the neoliberal policies of the 1990s were clearly reflected in the 1994 curriculum doctrine: freedom for schools and freedom of choice became evident at all levels. The most recent school curriculum, and the intensified evaluation practices in particular, demonstrate society's growing efficiency requirements and the increasing impact of the market economy (Salminen 2012). 
The American curriculum researcher, John D. McNeill (1985), has summarised the ideologies underlying the curriculum under four main categories. The humanistic premise aims to guarantee individually satisfying experiences for everyone. The curriculum is a liberalising process that responds to the need for mental growth. It is opposed to the bureaucratic control of teaching and education, centralised planning models, precise objectives related to content, excessive emphasis on the practical and connecting the school, for example, to the spheres of influence of working life or economics. The school has therefore lost its humanistic values, mental, aesthetic and ethical aspects have been neglected. The most critical speakers claim that schools are actually damaging to lowincome people and minorities.

Academic curricula partially aim to achieve the same results as in the humanistic tradition but the definition is more precise, pre-structured. Academic curricula stress that the curriculum should be seen as a tool that enables sciences, considered to be valuable and structured entities, to be offered to pupils. This then guarantees the best opportunities for further training. This aspect became stronger in the US after the 1950s. It is characterised by curricula and teaching materials developed by experts and it is based on the traditions of universities and strong faculties. A carefully structured curriculum affects the organisation of teaching in many ways. In the United States, it has been deemed necessary in light of the relatively low level of education among teachers. The German Lebrplan tradition has also highlighted this aspect. The Finnish grammar school system largely represented the principles of an academic curriculum. Its primary objective was to pave the way to university.

The technological perspective sees the curriculum as a production process and an extension of politics. It is used to fulfil certain requirements, and it cannot be neutral. The curriculum can make suggestions regarding teaching methods and organised experiences. The technological aspect has several levels. Narrowly speaking, it means arranging education using technical aids. It may mean computer-assisted learning, individual opportunities for study, using audiovisual tools. Various classifications of these can be carried out, but there is also a broader interpretation. This often refers to the efficiency of teaching programmes, methods and materials. Technology affects the curriculum in two ways: as applications and as theory. Applications are practices that make use of technological aids. On the theoretical level, it may be a certain means of defining and steering education and teaching. Narrowly speaking, in the latter case, the focus 
is on how teaching can be made efficient. What are the best methods and how can they be put into practice?

The fourth category presented by McNeill is the curriculum as a social construct and phenomenon. In this case, we take an optimistic view that the curriculum can be used to make a difference in terms of equality and changing the social structure of society. The curriculum is undeniably linked to the (local) community surrounding the school. This perspective has received support from critical pedagogical bodies as the social interpretation of the curriculum takes better account of cultural needs and the interests of minorities.

All of these definitions of curricula have a different relationship with the objective of promoting sustainable development, and they cannot be forced together. As such, the curriculum is not a clear, systematic and logical structure but a diffuse, unbounded and open one (Jackson 1992). According to William A. Reid (1999), the concept of the curriculum is troublesome in contemporary language because it can mean very different things to different groups of people. It has lost its position as a common context for everybody. As regards steering schools, the situation is challenging: school curricula do not mean the same thing to everyone.

\section{The Many Dimensions of the Educational Mission}

Educational work in schools includes a variety of target areas, which official curricula and development programmes aim to orient towards desired effects. These are the intellectual, emotional, social, physical, aesthetic and transcendental (mental or even spiritual) dimensions of education (Foshay 2000).

The majority of the discourse on school education since schools have existed has concerned itself with intellectual questions. Curricula and teaching materials have been prepared and schoolwork has been evaluated primarily on intellectual bases. One of the constant basic tasks of schools has always been to foster an increase in knowledge and skills. With the rapid development of industrial society, knowledge and learning have become increasingly important starting points of human activity, a position that has only intensified in recent decades with the arrival of the information society mindset. Most criticism of schools has focused on the ineffective teaching that has taken place in the last 60 years, inadequate learning outcomes and an inability to address the new demands of society as regards the growth of knowledge. Concerns about learning 
outcomes have been constant. Many school reforms, particularly those in the United States, have been initiated due to the poor learning outcomes achieved by schools. According to education researcher Reijo Miettinen (1990), talk of a crisis in schools has been a constant, established topic in Western countries since the 1950s, and researchers and politicians have involved themselves in this topic.

But to what extent is the goal of promoting sustainable development and wellbeing a purely intellectual one? Is it not more about values, attitudes and a permanent change in lifestyle, even a moral responsibility towards our planet? The objectives of promoting sustainable development cannot be reached simply by adding sustainable development courses to curricula, developing teaching materials or arranging recycling weeks at schools. A much deeper change is required in the culture of schools and education if real results are to be obtained. Merely increasing the amount of information will not in itself solve societal problems.

However, the emotional element referred to in the school debate has received much less visibility than the intellectual goal. Finnish educationalist Kari E. Turunen (1999) has aptly stated how purely rational planning leads to schools becoming "machines" that produce creatures with specific knowledge and skills. Increased youth depression and self-destructive lifestyles represent a challenge with regard to the duties of the education system. Despite the abundance of offerings and wealth of materials, Western education has not necessarily succeeded in making people happier. School shootings in the United States and in Finland have led to extensive public discourse on the lack of wellbeing among young people. In connection with these shootings, Finland's international PISA reputation has been cast in a critical light. British journalist Roger Boyes was interviewed by Finnish newspaper Helsingin Sanomat in November 2007 and he posed the following question: "You have an amazing educational machinery, but are children measured solely on their study attainment rather than in terms of their human development?"

The social imperative is employed to create an atmosphere of peace and democracy in the classroom and thereby in society more broadly, and also to guarantee that children have safe and pleasant group experiences as part of their schoolwork, thereby reinforcing societal structures. Social problems in schools-breaches of peace in the work environment, school bullying, school violence-prevent pleasant and productive intellectual learning. As such, even minor disruptions in social interaction in 
the classroom are immediately reflected in other reference areas and, in the worst case, may even prevent intellectual learning from taking place altogether. As regards the teacher's work, these problems are the greatest burden and hamper the achievement of educational goals.

Education in the physical capacity has occasionally been the subject of school-related debate. Often, it is limited to the area of physical education. However, physical capacity comprehensively controls the pupil's experience and may give rise to problems for the school. Schools have only a limited ability to ensure that children are able to enjoy the right kind of nourishment and get a good night's sleep, but children's problems in satisfying these basic needs become the immediate problem of the school. It would be a serious mistake to ignore basic human biological needs in school operations. For example, the amount of sleep that children get during developmental phases may be a crucial factor in enabling balanced growth, wellbeing and learning outcomes. Too little sleep is inevitably reflected in young people's school activities.

Studies have shown continuous fatigue to have both somatic and psychological effects on young people. Higher cognitive functions, such as abstract thought, are weakened, irritability and impatience increase, and emotional control deteriorates. School performance has also been shown to decrease with fatigue. Tired young people are also more prone to traffic-related accidents. Studies by the Finnish National Institute for Health and Welfare since the beginning of the 1980s have shown that the amount of sleep that young Finns get every night has been decreasing for three decades. In parallel with this, the number of people reporting a feeling of fatigue has increased. Based on these studies, it is easy to draw a conclusion: many of the problems related to the wellbeing of pupils are essentially physiological deficits, and attempts are made to address this problem using pedagogical techniques, new teaching materials and working methods. A hypothesis may be proposed that one of the key reasons behind the continuous increase in the number of pupils with special needs is the permanent lack of sleep caused by the hectic nature of society, with attempts made to address this problem in schools using an ever-expanding range of technologies and arrangements for special education. This solution is expensive and inefficient, and does not address the problem itself.

The physical imperative in the school context has also been given a completely new dimension by the culture of youth and experience, which has been intensifying since the 1970s. It has advanced through the media 
industry and at the behest of the media industry into classrooms without any consultation with teachers, accompanied by its own range of opportunities and problems. According to education sociologist Tarja Tolonen (1999), school children settle into school specifically as embodied actors. Girls and boys are engaged in a struggle for public space in educational institutions. The school is beginning to resemble a stage on which a type of social Darwinism is acted out. Appearance and clothing are scrutinised-gazing at others has become the most active thing to do.

Likewise, the aesthetic dimension of school education has been present to a minor extent in Western educational discourse. In the main, it has been the subject of occasional references by school architects and representatives of arts education and Steiner pedagogy. However, Foshay expands the topic to more than just art education. The school building, with its forms, colours and use of space, the study materials that are used, the texts that are read at school, the things that teachers say also produce features of the aesthetic experience. Awakening a sense of beauty is a classical tradition in education, and it can easily be overlooked when the aforementioned dimensions occupy time and space in discourse. The use of premises and the influence of architects has a significant impact on people's wellbeing in the workplace. Developing an aesthetic dimension to promote wellbeing comes up against resource problems.

The transcendental educational imperative is the least visible sub-area of the matrix in earlier curriculum theory. According to Foshay, it has even been directly neglected in school education. However, it is difficult to define precisely. Foshay has sought a historical basis for the imperative mainly within the scope of theology. The spiritual experience incorporates the same elements. In the context of learning, talk sometimes turns to key moments or "Eureka!" experiences. These refer to highly significant learning situations that may have a decisive effect on subsequent stages in the person's life. For many pupils, an individual positive and successful event at school may lead to a choice of profession, provide the basis for a career in research or lead to a lifelong hobby.

A continuous struggle is taking place in society between these six educational objectives: on the one hand, the debate centres around the importance of school education; on the other hand, the focus is on the roles of different subjects in relation to the objectives. Experts from various fields and representatives of educational disciplines take a stand on the meanings of the imperatives with different emphases and demands. 
Societal conflicts can even be exploited as a means of justifying the importance of a particular subject and imperative in school programmes. One example that may be mentioned of this is the rhetoric entered into by representatives of art and craft subjects to safeguard the positions of these subjects within the school-they talk of their subjects as means of mitigating social problems and increasing the wellbeing of young people. In this context, there is absolutely no intention to contest the findings made by educators of sports and art of the ability of sports or arts education to enable emotional unloading, the potentially empowering effect of such unloading or the importance of music education as a socially constructive activity. However, it should not be forgotten that there are many other subjects that can produce very similar experiences among young people. Demands to increase the amount of teaching of art subjects in schools with the motive of preventing school shootings are based on an absurd causal inference and can be considered an exploitation of a societal crisis to advance personal objectives. Using equivalent logic, almost any societal episode could be explained in the desired manner and the arguments could be used to promote a certain type of activity in schools (Salminen 2012).

The substance of subjects as a feature of educational goals and as a factor in the selection of the content that is taught is the target of ongoing ideological debate. What should be taught to young people? What should be set aside and which new responsibilities should the school assume? In Finland, the struggle over content is particularly intense when discussing different subjects and the number of hours spent on each subject. In the modern school system, the number of hours dedicated to each subject is a representation of the purpose of the school. All of the subjects and learning entities taught in school have their own development histories and current societal connections. Various interest groups seek to defend the position of a certain subject or content in the curriculum.

The amount of information produced by universities and the skills valued by society are channelled and administered to young people via school timetables. For this reason, numerous societal interest groups and stakeholders involve themselves in this distribution of scientific knowledge for external use and take their own positions on such distribution. In a sense, the struggle is ultimately over control of the worldview and future of pupils. The aim of promoting wellbeing is a typical broad and 
multi-dimensional educational issue, which should be defined more precisely: what does it mean for the work of schools? Which subjects are responsible for the promotion of its objectives? How is it realised in practice? To what extent is it debated and how can the results be assessed?

In addition to these official objectives, school culture consists of more than just educational objectives and contents. Questions about rights and obligations, rewards and punishments handed out by the school, the rules that are used, the limits of responsibility and freedom are everyday educational matters, regardless of the subject. Often, there is no single clear and correct solution, meaning that decisions must be made very quickly. Throughout the day, the teacher will be called upon to resolve numerous moral questions, whether large or small. As regards day-today work in schools, these numerous, diverse and ever-changing priorities and new requirements have led to a challenging problem of balance. When school conditions are considered to encompass the realisation of a "hidden curriculum"-instilling values, beliefs and practices that are not stated as official educational goals-the educational function becomes even more complex to carry out and to analyse. At the same time, it should be noted that the demarcation between the official and hidden curricula is not always clear (Broady 1994).

Education sociologist Risto Rinne (1987) has published an article describing the permanently ambiguous and interpretive nature of curricula, which are accompanied by continuous compromises, as a type of societal buffer. It is as if curricula were not intended to be realised as such. The apparent harmony that appears in them can be a means of satisfying societal demands for change that have emerged and are triggered by putting pen to paper. At the same time, societal pressures for change are tempered. The educational administration is also granted a form of absolution. It has done its work and can attend parliamentary debates or make media statements to the general public about how a topical phenomenon in environmental education has been taken into consideration in schools (better than before) by means such as increasing the content of environmental education. The same people are highly unlikely to be called upon to justify the actual impact of this change in the curriculum several years or decades after the fact. The entire school administration and the parties that benefit from schools all assume their own roles in this apparent curriculum change and "poetry". 


\section{Preconditions Imposed by Practicality}

The third level of the hierarchy in Labaree's (2010) classification is constituted by actual teaching, practical educational activities that take place in schools and as part of the operations organised by schools. It is only at the third level that real impact can begin. Realising the school's educational objectives is always dependent on the degree of commitment of teachers. It is their responsibility to promote the objectives that are set. They are the key group in promoting the objectives of sustainable development.

At the same time, the teacher's educational task is extremely complex and contradictory. During one lesson and one school day, the teacher could theoretically run into thousands of small variables between which education must take place and values and priorities must constantly be selected. Although the work in traditional school classrooms is formulated into a reasonably well-defined activity by means of the prevailing pedagogy, the curriculum and the physical classroom space-in order for it to be at all possible and to some extent manageable and predictable-an almost infinite number of factors are always present in educational work. The majority of these support school activities, but many are also in a permanent state of conflict with each other. However, there is often no direct recognition of the complex and tense nature of the teacher's circumstances when new large-scale educational tasks and work development requirements are set for the school.

Every teacher who has done practical teaching work for any length of time will have come across these conditions of their work and quickly discovered the multitude of constraints imposed by them: pupils' interests and abilities vary, as do learning conditions. Education should be individual, but it takes place in a group. Questions about what, why and how lead to complex ideological, psychological and pedagogical tangles. Educational scientist William A. Reid (1999) has defined seven different classifications of variables affecting the implementation of the curriculum when teaching is arranged (how). These are the concepts of knowledge and knowing, truth-values in different subjects, child development, the nature and characteristics of the teacher, the interaction between pupils and teachers, the role of teachers and effective teaching, as well as the curriculum itself.

Many material factors complicate teaching work. There is generally too little teaching time in relation to the objectives. Classrooms 
are cramped, making individualisation more difficult. In large units, it is necessary for schoolwork to be fragmented for logistical reasons by means of timetable and space arrangements. Teaching tools and materials are rarely sufficient, equipment does not function reliably, support staff are rarely available. The assessment methods determine the content in advance. This in turn makes it difficult to teach "meta-skills", which cannot be measured by end-of-term tests. The list of factors such as these that restrict teaching work and limit optimal learning by children is almost endless. In addition, the opportunities open to educators and young people to modify these conditions are usually rather limited. The framework is largely determined in advance. Even individual schools rarely have the possibility to make an appreciable difference. It is hardly ever possible to push through practice under ideal conditions. Naturally there are differences between educational institutions, school districts and municipalities. Some schools are worse off than others.

The work of teachers is constantly based on highly uncertain knowledge in ever-changing conditions, unlike the work of professionals in other fields such as medicine or law. In the latter fields, each ongoing work process can often be narrowed down and isolated quite unambiguously, quantitatively, qualitatively and technically. In the work of school teachers, this is rarely possible. Schoolwork is carried out in group form: numerous individual and societal processes, communicative states and problem-solving efforts are underway on different levels simultaneously. By nature, these are all societal, psychological, ethical, moral, didactical and technical. In addition, spontaneous, accidental and irrational situations caused by external variables often arise in educational situations and the teacher-as the person responsible for the situation-must find a way to manage and resolve these.

Foshay (2000) has posited a theoretical number to illustrate the complexity of the reality produced by different variables. According to him, 145,800 interactions can be counted between content, objectives and practical questions. Of course, some of these are likely to be meaningless in practice, but the vast majority correspond realistically to work in a school. If all of these contents, means and practical processes are identified for every individual person in a classroom of thirty pupils, the job would involve managing millions of variables. Foshay's proposed calculation of the interactions between the variables in the matrix is naturally pure illusion. Nonetheless, it is a tangible illustration of the incredible complexity of work in schools (value work), the difficulty in managing 
the work and the sensitivity to disruption of numerous situations. At the same time, it indicates the deeply problematic gap between theory and practice. Scientifically, it is difficult to even estimate which factors in the classroom are relevant at any given time, or to decide which of them should be prioritised and how such prioritisation should be carried out.

Work to reform schools and teaching is also not subject to clear stopping rules. There are no criteria that would enable us to know when the problem resolution process is complete and the problem has been solved. The search for the solution to a wicked problem can be brought to an end by factors other than the discovery of a complete analysis framework. These include time, financial resources and people's ability to cope. Often, patience runs out and "a sufficiently good solution" is settled upon. These are often hasty compromises or political preferences. For this reason, attempts to bring about change in schools very often merge gradually into the prevailing system. According to a frequently referenced viewpoint, teachers change development projects to a greater extent than the projects alter teachers' activities.

At worst, the change has been confined to curriculum texts, even though it has been the subject of scientific reporting in terms of development outcomes. In many cases, practical work to carry out development projects in schools has discontinued before the project's final report has been printed for public distribution. Development cycles in modern schools have accelerated. The next reform begins before the previous one has been completed and evaluated. At worst, the next reform buries the achievements of the previous reform and cancels out the development work that was done. Real results should be measured several years after operations are initiated. However, this interval is generally too long from an administrative perspective.

As regards research and steering, development work in schools also comes up against serious questions of reliability. Development projects are often evaluated by the same body that then carries out the reform, whether these are school officials or interventions by researchers. The results are evaluated in terms of what was intended to be implemented in the project and not in terms of any other changes or even opposing changes that affected the school as a result of the project. In some cases, additional financing may depend on positive results. Intervention projects that are very narrow in scope are unlikely to even be aware of or follow up on the school's activities in a wider sense. School development very rarely, if ever, satisfies the prerequisites for reliability as required for basic scientific research. 
The majority of teachers do adopt new tasks and methods, providing that they really help them in often difficult and complex circumstances. From their perspective, "improvement; new technology or method offered" has not always brought the help that was promised. On the contrary, development work very often begins by generating additional work and new problems that must be solved by the school community. This complicates the identification of clearly positive results. At the same time, the objectives of development work remain vague. As a frequently recurring cycle, this type of "development work" may erode the credibility of the key players when they promote new objectives and practices.

For educators, there is a constant danger of such disappointment. Poorly managed, vague curriculum reforms may lead to very negative results in school activities. They can put a stop to educational innovation and may even undermine teachers' commitment. In recent decades, curriculum reforms have been initiated before the previous reform has been properly completed and evaluated. From the perspective of the history of education, it can be justifiably stated that implementing school education in this manner may reduce the commitment of key stakeholders and can lead to precisely the opposite result than that targeted by the reforms: resistance to change, frustration and development fatigue. Achieving permanent results requires long-term work and commitment to the objectives. It is ultimately a question of the adequacy and allocation of mental capacity. High teacher turnover, a desire to leave the sector and a reduction in job satisfaction are severe symptoms of school culture problems that cannot be explained away solely by economic factors.

\section{Pupils' Learning}

The final level in Labaree's (2010) hierarchy_and the most important one In terms of the actual outcome of educational objectives-is pupils' learning. Even if school reform on the rhetorical level receives widespread support throughout the formal and complex institutional structure and teachers are also committed, it is necessary for pupils to be motivated and able to embrace the goals that are set. After all, school effectiveness is simply a question of what type of knowledge, skills, metacognitive thinking and other educational goals have been permanently assimilated by pupils. In this case, the objectives of sustainable development would begin to appear in society decades later in the form of measures intended to achieve the desired objective. 
With regard to pupils' learning, the situation has become even more challenging in recent decades. While school functions have expanded, traditional school education has been subjected to criticism in many forms. Teacher's authority has also weakened. According to Mika Ojakangas (1997), a philosopher, a trend began at the end of the nineteenth century whereby the freedom born of discipline and morality was gradually abandoned and a shift began towards the death of authority and-in one sense-the end of education. In the Western ideology of developmental thinking and liberalism, the destruction of authority was a condition of democracy. A belief also took hold within education that children can get by without authority, which could be replaced by persuasion, experts and technology. American researcher Maureen Stout (2000) has stated in her book, Feel-Good Curriculum that the United States has developed in exactly the same direction. How boosting selfesteem has become one of the most important goals of the school. At the same time, the traditional functions of a public-sector school-civic education, democracy, provision of information and skills-have become weaker in parts. The objective of enabling the creation of a school community has been marginalised due to emotional issues.

Education should be flexible, motivating, happy and playful; it should be driven by the child and the situation. For some commentators, school satisfaction will increase as learning becomes more fun and schools select a pleasant atmosphere of freedom. The correlation between a pedagogy of play and good learning outcomes appears to be obvious up to a certain limit, but this growing demand for freedom and openness represents a substantial challenge for schools. In basic, everyday work, it is difficult to make some content ever more motivating and the school is thus forced into the difficult position of a service provider. The English term, "edutainment", describes this phenomenon, in which learning is made into industrial entertainment. When parallel entertainment production processes are underway in other areas of society, such as communication and politics, the end result may be-in the extreme case-the end of education. All prohibitions and restrictions are considered undesirable, all educational norms can eventually be relativised as being somehow restrictive of children's efforts.

German child psychiatrist Michael Winterhoff (2008) has suggested that children today are increasingly irresponsible and narcissistic. A type of symbiotic parenthood has taken the place of traditional parental authority. Children are allowed to act according to their desires. 
In the event of a conflict, somebody else is always to blame: another child, the teacher, the teaching method, anyone else but the parent's own child. Similar remarks have been made by Danish psychologist Bent Hougaard (2005). He has publicised the concept of curling parenting. Hougaard uses this term to refer to the principle of education in which every obstacle and problem has been cleared from the child's path. The result is selfish people who cannot withstand setbacks.

The findings of youth researchers indicate that school curricula and everyday youth leisure activities are living separate lives from each other. The gap between young people's experience of school, with its strict timetables, and the other spheres of their lives seems to be the real problem of late-modern youth. Researchers in the sector propose a new form of communication to solve this problem: interactive situations would become learning situations in themselves. This gap between the traditional school and the world of experiences in youth culture cannot, however, be bridged by special arrangements, technology, didactics or fine-tuning of teaching. The principles of working from a starting point based on pupils' experiences and living environments and emphasising the situational nature of teaching cannot be summarised to create unambiguous operating instructions; teachers must trust themselves and their own life experiences as representatives of the adult generation. Researchers should overhaul the obstacles to their own thinking and routines.

Juha Suoranta, a Finnish researcher representing the critical pedagogical perspective, goes even further. In one of his articles, he proposes including hip-hop culture in school education. According to Suoranta (2005), hip-hop culture represents self-motivation and autonomy, self-determination, cultural dialogue among friends, societal criticism and commercialism. It would challenge the state-guided school's functions of teacher-led monologue and maintenance. Suoranta defines hip-hop as "popular politics". It could serve as a means for political education and could restore interest among young people towards societal issuesmany studies have shown that young people shy away from wielding social influence.

\section{LEARNING FROM MisTAKES}

Naturally, studies based on school history cannot determine how the objectives of promoting sustainable development and wellbeing should be arranged in schools in the future. The issue revolves around 
fundamental values, which no discipline is able to resolve. David Hume's classic guillotine slices through the neck of this prophecy: it is not possible to make statements about how things ought to be on the basis of how they are now. However, some cautious advice can be provided by research to support the effort.

Firstly, it should be noted that no clear means or scientific methods have been identified to facilitate rapid developments in the complex public-sector school system throughout its 150-year history. According to Cuban (1992), the system is a contradictory entity in which historically inherited, political, ideological, cultural factors related to resources, legislation and pedagogical techniques-partly in opposition to each other-are in constant interaction with each other preventing, rejecting, hampering and hiding change. Sarason (1990) and Labaree (2010) warn against excessively ambitious projects in schools. They will not succeed.

The proposal of the school system as a pioneer of societal activity is impossible to realise in practice. It would require the power relations in the system to be dismantled, a complete change to take place and the ability to determine who has access to the predictive ability that could enable current educational traditions to be dispensed with. School can never start with a clean slate. In addition, it must be remembered that the main structures in the system are long-term reflections of the social conditions in each period. The classical rectangular classroom shape was inherited from times that emphasised control over pupils (the fear of God). The compulsory nature of school, the obligation to study and the precise distribution of lessons have arisen to create central state control and regulation (control over school curricula). The didactics of masses, the pedagogy of the times, textbooks and workbooks, standardised tests, final assessments and many classroom practices are, in turn, technologies that have been shaped by the standards of industrial society. Current psychodidactical management techniques are based on scientific paradigms. All of these layers are stacked up in the school's complex operational culture. Changing them would require radical measures. The curriculum and pedagogy are not able to do this, although this is often expected-or even demanded-of them. Resolving environmental problems, improving public health, increasing world peace are societal objectives. They must be addressed through policy. Schools can only support these efforts to a minor extent (Salminen 2012).

On the basis of research into the history of education, the opportunities for educational institutions to keep up with accelerating change 
are, in many respects, limited or non-existent. Due to their contradictory structures, schools are condemned to play catch-up. Whether this gap has deepened along with external reality beyond the school is largely a matter of interpretation and perspective. When researchers demand "the development of the entire operating model of the school" in speeches directed at the general public, it is worth asking whether they have any knowledge of the system they are talking about.

Research into school history has identified a number of variables that influence the realisation of new educational goals at school level (Tyack and Cuban 1995; Cuban 2003; Labaree 2010; Salminen 2012). First of all, the timing of pedagogical reform activities in relation to changes in society's means of livelihood, technological development and the needs of working life play a very important role. This is an eternal horizon problem in school pedagogy. How far from the past or from other cultures and countries should ideas be drawn? How far into the future can the justifications be relied upon? When should school reform be delayed to allow circumstances to stabilise? Reform projects may be forced into marginal positions by rapid changes in surrounding conditions in a short period of time.

Secondly, reform also requires its own internal continuity and "freedom to work". Otherwise, there is a danger that the activities will be suffocated by other variables. In terms of actual reform, new external variables often impose new boundary conditions on development work. This can be frustrating and tiring for key players. They will switch to other sectors. This risk is always present in the development of school curricula. When key players suffer fatigue, development activities often fade rapidly.

Thirdly, strong development of the curriculum requires financial resources. Economic forecasting is difficult, as the entire twentieth century has demonstrated. Even in peacetime, economic downturns have significantly affected school development work. This was experienced when Finland's compulsory school system was being introduced in the 1970s and the oil crisis hit. Several reform activities and pledges had to be cut. The recession in the 1990s hampered and paralysed pedagogical development in Finnish schools for a long period. In the 2010s, school reform is once again being overshadowed by a steep economic downturn. The consequences for education have been varied and fluctuating priorities with regard to financing, objectives and development. 
It is completely unrealistic to think that the development of schoolwork could be realised in the form of a voluntary vocation over long periods of time, driven purely by developmental interest or in accordance with operational research. Of course, the history of pedagogy features some of these altruistic people and surely they must exist at all times in some measure. Building the entire system and development work around such personal enthusiasm is, however, a naive idea. The casting of a lowpaid, strictly managed and monitored civil servant by research literature in the educational field as a dynamic, creative, socially innovative agent of change-in the age of the harsh global market economy with intensifying performance targets - is a romantic, implausible, if not absurd, premise.

Fourthly, reform activities require the emergence of a favourable atmosphere to support development activities. Even if such a condition existed at the beginning of the development work, there is no guarantee that the same atmosphere will prevail a few years later. This can even apply to the wider cultural climate of pedagogy following a societal crisis. For educators, there is a constant danger of such disappointment. Poorly managed, vague curriculum reforms may lead to very negative results in school activities. They can put a stop to educational innovation and may even undermine teachers' commitment. In recent years, curriculum reforms have been initiated before the previous reform has been properly completed and evaluated. Achieving permanent results requires longterm work and commitment to the objectives. It is ultimately a question of the adequacy and allocation of mental capacity. High teacher turnover, a desire to leave the sector and a reduction in job satisfaction are severe symptoms of school culture problems that cannot be explained away solely by factors related to remuneration.

Fifthly, school reform requires strong support at the school administration level. Changes in the administration have an immediate impact on the operational culture of schools but schools have minimal opportunities to influence the way in which administration is organised. When political trends change, schools' priorities often change too. Such sudden decisions may cause counter-reactions among teachers to resist development, as they relate most directly to those who in reality have initiated some activity. Many projects that have been initiated begin to waste away in such a situation, with the consequence that the next curriculum reform is more likely to be given a more cautious reception. Poorly managed reforms consume the credibility of subsequent reforms. At the same time, at the level of individual schools, cynical teachers who are stuck in 
traditional ways receive ammunition to use against development within the working community, bringing the weight of experience to bear in order to show that the work is unnecessary over a time horizon of a few years.

Sixthly, individual educational institutions are always dependent on their pupils and the support of their parents. This is another of the eternal problems surrounding school development work. New innovations must enjoy the support of stakeholders in order to enable a break with tradition and to arouse interest in schools. Otherwise, the force of tradition will take hold or suck the reform in very quickly. If, however, the reform effort is too strong, it can easily end up becoming detached and being seen in a strange light throughout the system. Nobody can predetermine the correct intensity of intervention. According to Labaree (2010), consumers will eventually decide what kind of education they desire for their child. Their assessment has a greater impact than the new rhetorical efforts of school reformers.

Seventhly, teachers must be fully committed to long-term reform and must solve the new difficulties that it causes. This is a typical problem in the field of education. It is always easy to be impressed by new things for a certain period of time. Interest in the school's activities among external parties and positive publicity in the media are likely to motivate the key players during the early stages and also encourage additional efforts. Within a few years, however, media interest-perhaps due to the very nature of media-will fade, leaving everyday schoolwork to continue as normal. If, at the same time, additional financial resources gradually fade, development work will lose its appeal.

The most important factor for the development of school teaching comes from the top level of the hierarchy of educational institutions: universities. The most decisive aspect is the attitude taken by institutes of higher education to new priorities. English School historian Ivor S. Goodson (2001) has presented a theoretical model of the way in which structural changes to the educational syllabus often occur. According to him, the attitude taken by institutes of higher education is highly significant in terms of the success and permanence of the change. Subjects for which university faculties provide traditional support-a subject department and professorships-hold the strongest position in schools. These faculties monitor and regulate teaching activities in educational institutes lower down the chain by defining the core contents. For this reason, it is difficult for new subjects and objectives to gain a foothold in 
school programmes because the scientific background support is weak or non-existent. One key conclusion to be drawn from this is that the objectives of sustainable development should be given greater priority in universities and should cover the cultures of various faculties. From there, these aims would eventually make their way down to schools.

The public-sector educational institution, which was built around the standards of the Christian curriculum, Prussian regulation (state-centric nature) and the industrial society and constructed for over a hundred years, is undeniably facing a growing challenge. According to William A. Reid (1999), traditional curriculum-based thinking is struggling to identify genuine opportunities to influence the activities of schools. The traditional basis of the curriculum is beginning to deteriorate or at least to weaken, without the system currently having a new, sustainable foundation, scientific paradigm or other basis that could reliably support it. The promise of the opportunities of open learning environments, the individualisation of teaching and non-formal learning winning out have, in many respects, remained unfulfilled, and some are in serious conflict with other educational targets set for schools.

Since the 1990s, societal policies that emphasise individual choices have grown in importance and begun to affect educational structures everywhere. At the same time, the rhetoric around education has begun to include terms such as profit centre, customer relationship and quality. The change may reflect a deeper shift in which it may no longer be a case of comprehensively analysing education and developing society. Instead, it may represent a movement towards an expert-orientated, technocratic system of governance, with various specific indicators and technologies employed in an attempt to exert control (Salminen 2012).

In such a situation, efforts to promote the goals of sustainable development and wellbeing at school level can only be approached with very cautious aspirations. Schools can play a small part, but they cannot do any more than that on their own. Unrealistic visions do not benefit anybody.

\section{REFERENCES}

Broady, D. (1994). Den dolda läroplanen. Stockholm: Symposion.

Cremin, L. A. (1987). American Education. The Metropolitan Experience 18761980. New York: Harper \& Row. 
Cuban, L. (1992). Curriculum Stability and Change. In P. W. Jackson (Ed.), Handbook of Research on Curriculum. A Project of the American Educational Research Association. New York: Macmillan.

Cuban, L. (2003). Why It Is so Hard to Get Good Schools. New York: Teachers College Press.

Elmore, R. F., \& McLaughlin, M. W. (1988). Steady Work, Policy, Practice and the Reform of American Education. Santa Monica, CA: RAND Corporation.

Foshay, A. W. (2000). The Curriculum: Purpose, Substance, Practice. New York: Teachers College Press.

Goodland, J. I. (1979). Curriculum Inquiry. The Study of Curriculum Practice. New York: McGraw-Hill.

Goodson, I. S. (2001). Opetussumnnitelman tekeminen. Finland: Joensuu University Press. (in Finnish).

Helsingin Sanomat 18.11.2007, D3.

Hougaard, B. (2005). Curlingföräldrar och Servicebarn. Stockholm: Bokförlaget Prisma.

Jackson, P. W. (1992). Conceptions of Curriculum and Curriculum Specialists. In P. W. Jackson (Ed.), Handbook of Research on Curriculum. A Project of the American Educational Research Association. New York: Maxwell Macmillan International.

Kosunen, S. (2016). Families and the Social Space of School Choice in Urban Finland. Helsinki: University of Helsinki.

Labaree, D. F. (2010). Someone Has to Fail. The Zero-Sum Game of Public Schooling. Cambridge: Harvard University Press.

McNeill, J. D. (1985). Curriculum: A Comprehensive Introduction. Boston: Little Brown.

Miettinen, R. (1990). Koulun muuttamisen mahdollisuudesta. Analyysi opetustyön kehityksestä ja ristiriidoista. Helsinki: Gaudeamus.

Ojakangas, M. (1997). Lapsuus ja auktoriteetti. Pedagogisen vallan historia. Helsinki: Tutkijaliitto.

Reid, W. (1999). Curriculum as Institution and Practice. Essays in the Deliberative Tradition. New Jersey: Lawrence Erlbaum Associates.

Rinne, R. (1987). Onko opetussuunnitelma ideologiaa-Opetussuunnitelma aikakautensa sosiaalisten ehtojen raamittamana skenaariona? In P. Malinen \& P. Kansanen (Eds.), Opetussuunnitelman tutkimukselliset kebykset. Helsingin yliopiston opettajankoulutuslaitos.

Rittel, H., \& Webber, M. (1973). Dilemmas in a General Theory of Planning (Policy Sciences 4/1973).

Rosa, H. (2009). Social Acceleration: Ethical and Political Consequences of a Desynchronized High-Speed Society. In H. Rosa \& W. E. Scheuerman (Eds.), High-Speed Society. Social Acceleration, Power and Modernity. University Park: The Pennsylvania University Press. 
Salminen, J. (2012). Koulun pirulliset dilemma. Helsinki: Teos.

Sarason, S. (1990). The Predictable Failure of Educational Reform: Can We Change Course Before It's Too Late? San Francisco: Jossey-Bass Publisher.

Schwab, J. J. (1978). Science, Curriculum and Liberal Education. Selected Essays. Chicago: University of Chicago Press.

Simola, H. (2000). Firmly Bolted into the Air: Wishful Rationalism as a Discursive Basis for Educational Reforms. In S. J. Ball (Ed.), Sociology of Education. Routledge: Major Themes.

Stevenson, R. B. (2007). Schooling and Environmental/Sustainability Education: From Discourses of Policy and Practice to Discourses of Professional Learning. Environmental Education Research, 13(2), 265-285.

Stout, M. (2000). The Feel-Good Curriculum. The Dumbing Down of America's Kids in the Name of Self-Esteem. Cambridge: Da Capo Lifelong Books.

Suoranta, J. (2005). Hiphopin poliittinen epäpuhtaus. In T. Hoikkala, S. Laine, \& J. Laine (Eds.), Mitä on tebtävä. Nuorison kapinan teoriaa ja käytäntöä. Loki-kirjat.

Tolonen, T. (1999). Hiljainen poika ja äänekäs tyttö. Ääni sukupuoli ja sosiaalisuus koulussa. In T. Tolonen (Ed.), Suomalainen koulu ja kulttuuri. Tampere: Vastapaino.

Turunen, K. E. (1999). Opetustyön perusteet. Vaasa: Atena.

Tyack, D., \& Cuban, L. (1995). Tinkering Toward Utopia. A Century of Public School Reform. Cambridge, MA: Harvard University Press.

van der Loo, H., \& van Reijen, W. (1992). Modernisierung, Projekt und Paradox. München: DTV.

Winterhoff, M. (2008). Warum unsere Kinder Tyrannen werden? Die abscaffung der Kindheit. Gütersloh: Gütersloher Verlagshaus.

Open Access This chapter is licensed under the terms of the Creative Commons Attribution 4.0 International License (http://creativecommons.org/licenses/ by $/ 4.0 /$ ), which permits use, sharing, adaptation, distribution and reproduction in any medium or format, as long as you give appropriate credit to the original author(s) and the source, provide a link to the Creative Commons license and indicate if changes were made.

The images or other third party material in this chapter are included in the chapter's Creative Commons license, unless indicated otherwise in a credit line to the material. If material is not included in the chapter's Creative Commons license and your intended use is not permitted by statutory regulation or exceeds the permitted use, you will need to obtain permission directly from the copyright holder.

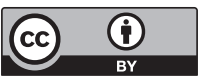

